\title{
Una revista con amplitud metodológica y con proyección internacional
}

\author{
Editorial
}

Iván Montes Iturrizaga

Revista

Educación y Sociedad

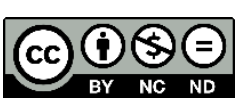

I ACEES
La Academia de Estudios Educativos y Sociales (ACEES) pone a disposición de la comunidad académica su publicación científica Revista Educación y Sociedad; la misma que cuenta ahora con el aporte de contribuciones del ámbito internacional que se suman a los autores nacionales.

Del mismo modo, cabe resaltar que en esta entrega seguimos con la apuesta por la diversidad teórica y metodológica que transita por estudios teórico críticos, revisiones y estudios empíricos tanto cuantitativos como cualitativos. En este marco, también contamos en este número con un artículo, que, desde una perspectiva integradora entre la psicología y la historia discute la mentalidad peruana (Ser nacional) que devela la actual pandemia por el COVID-19 (P. Abarca). Otros estudios estudian desde aproximaciones cuantitativas las actitudes hacia el machismo (D. Olarte) y el liderazgo percibido en instituciones educativas desde una aproximación cuantitativa (G. VelaQuico \& T. Cáceres-Coaquira). Asimismo, hemos seleccionado un estudio (F. Arias \& O. Betancur) orientado a la enseñanza a través de casos de estudio en entornos universitarios.

Ya desde el punto de vista cualitativo empírico ponemos a su disposición un estudio que aborda la participación social de la comunidad educativa realizado en Venezuela (F. Heredia).

Esperamos seguir recibiendo sus contribuciones, comentarios, propuestas y consultas con miras a los próximos números. Asimismo, hacemos votos porque en el futuro cercano se cristalicen nuestros anhelos por editar números monográficos en convenio con organizaciones del ámbito local e internacional. 